Revista de Estudios Histórico-Jurídicos

[Sección Historia del Derecho Hispano-Indiano]

XXXIII (Valparaíso, Chile, 2011)

[pp. $445-461]$

\title{
INNOVACIONES EN EL SISTEMA JUDICIAL DEL ANTIGUO RÉGIMEN POR EFECTO DE PRÁCTICAS JUDICIALES Y ADECUACIONES INSTITUCIONALES REALIZADAS EN LAS VISITAS DE IDOLATRÍA EN LIMA DURANTE EL SIGLO XVII
}

["Innovations in the Old Regime's Legal System Due to Legal Practices and Institutional Adjustments Performed in the Idolatry Extirpators in Lima During the $17^{\text {th }}$ Century"]

\section{Macarena Cordero Fernández* Universidad Adolfo Ibáñez}

\begin{abstract}
RESUMEN
Durante el siglo XVII en la diócesis de Lima se desarrollaron las visitas de idolatrías, que eran tribunales itinerantes cuyo objeto consistía en velar por la pureza de la fe, y someter a proceso y penalizando a los indios sospechosos y culpables de apostasía. Sin embargo, como se trató de una institución dirigida a los indígenas, su procedimiento y sistema punitivo se vieron reformulados por las autoridades coloniales en atención a las especiales circunstancias etnográficas, sociales, políticas y culturales de la población andina, como también, a la influencia del estatuto protector indígena, el que debía ser respetado por los agentes coloniales. Lo anterior implicó una serie de modificaciones al procedimiento inquisitorial, al sistema de castigo y de defensas que generaron fisuras, reinterpretaciones y resignificaciones por los agentes coloniales, relativo al orden y Derecho penal
\end{abstract}

\begin{abstract}
During the $17^{\text {th }}$ century, idolatry extirpators, that were itinerary courts, purpose of which was to watch over the pureness of faith, and to prosecute and penalize the Indians suspected and liable for apostasy, were performed in the diocese of Lima. However, since this institution was meant for the native people, the colonial authorities had to reformulate its proceedings and punitive system due to the special ethnographic, social, political and cultural aspects of the Andean peoples, as well as due to the influence of the indigenous protector statute, that had to be respected by the colonial agents. The aforementioned entailed a series of modifications to the inquisitorial process, to the punishment and defense system that resulted in fissures, reinterpretations and resignifications among the Colonial agents regarding the order and Criminal Law of the Old Regime which gave rise to
\end{abstract}

* Profesora en el Departamento de Historia de la Universidad Adolfo Ibáńez. Dirección postal: Diagonal Las Torres 2640, Peñalolén, Santiago, Chile. Correo electrónico: maria. cordero@uai.cl 
del Antiguo Régimen, que dio lugar a un proceso penal que es posible calificar de protomodernizante.

Palabras Clave

Protectores de naturales - Defensores - Protección jurídica de los indígenas. Derecho procesal y penal inquisitivo. a criminal process that can be labeled as proto-modernizing.

\section{KEYWORDS}

Indigenous people protectors - Defense - Legal protection for the native people. Inquisitive procedural and criminal law.

Recibido el 27 de julio y ACEPTADo el 12 de agosto de 2011

\section{RESIGNIFICACIONES DE LAS PRÁCTICAS JUDICIALES INDÍGENAS}

La Corona castellana persiguió la religión indígena no sólo por consistir en una práctica de carácter idolátrico, sino porque en ella la participación comunitaria renovaba los sentimientos de identidad cultural, y también autorizaba aquellos roles de articulación social prehispánica que, en las primeras décadas de la conquista y colonización, la administración indiana permitió mantener a las comunidades locales. En buenas cuentas los colonizadores espirituales debieron consensuar con los jefes locales ciertas prácticas para poder evangelizar, cuestión que registra Joseph Arriaga ${ }^{1}$. Sin embargo, transcurridas las décadas, se dio inicio a una ofensiva desde la Corona dirigida a establecer la ortodoxia religiosa en los territorios extra peninsulares. Más aún si tomamos en consideración las diversas noticias que se tenían del mal comportamiento de los españoles, de la falta de doctrina de los indígenas, como también, de la pervivencia de las idolatrías de este grupo indiano.

Frente a ello, la Iglesia y la Corona tuvieron que articular estrategias para extirpar idolatrías, pero muchas veces se encontraron con una serie de inconvenientes, fuesen de carácter económico, falta de funcionarios capacitados para llevar a cabo la tarea, desacuerdos entre las diversas autoridades reales y eclesiásticas coloniales, o bien la desidia por parte de quienes tenían a su cargo el deber de velar por la ortodoxia. Dificultades que se deben enmarcar en la dinámica de un círculo de causalidades de presiones y resistencias sociales, puesto que entraron en juego una serie de procesos sistemáticos de de-culturación y a-culturación, tendientes a poner fin a las prácticas idolátricas de los indígenas.

Así en los espacios con grandes concentraciones indígenas cercanas a los centros de poder la solución a este conflicto vino determinado por la institucionalización de sistemas judiciales desde la Iglesia. El provisorato en México y las visitas de idolatrías en el Perú, constituyeron tribunales de justicia cuya competencia era la relativa a sancionar las prácticas alejadas de la ortodoxia y de aquellas que dieran pábulo para una herejía, tales como las borracheras, amancebamientos, entre otras. Por lo demás se trata de los casos más conocidos y trabajados precisamente por

\footnotetext{
${ }^{1}$ Arriaga, Pablo de, La extirpación de las idolatrías en el Pirú (Estudio preliminar y notas de Urbano, Henrique, Cusco, Centro de Estudios Regionales Andinos Bartolomé de las Casas, 1999).
} 
el impacto que generaron en los respectivos espacios en los que se desarrollaron, por la forma de en que se estructuraron, como también por su organización e institucionalización que implicó su propia autonomía ${ }^{2}$.

En tal sentido, durante el siglo XVII en la diócesis de Lima se desarrollaron las visitas de idolatrías - tribunales itinerantes que se organizaron a base de la Inquisición Española y las visitas de distrito ${ }^{3}$ - que tenían por objeto velar por la pureza de la fe, sometiendo a proceso y penalizando a los indios sospechosos y culpables de apostatas. Sin embargo, como se trató de una institución dirigida especialmente a los indígenas, su procedimiento y sistema punitivo se vieron reformulados por las autoridades virreinales en atención a las especiales circunstancias etnográficas, sociales, políticas y culturales de la población andina, como también, a la influencia del Estatuto Protector Indígena, el que debía ser respetado por todos los agentes coloniales.

Lo anterior implicó una serie de modificaciones al procedimiento inquisitorial, al sistema de castigo y de defensas que generaron fisuras, reinterpretaciones y resignificaciones por los agentes coloniales, relativos al orden, Derecho penal y procesal del Antiguo Régimen. Aún más, a partir de tales transformaciones es posible deducir que tras las prácticas judiciales y discursivas se produjeron, por una parte, tensiones entre los agentes eclesiásticos y protectores de naturales quienes utilizaron estratégicamente los procesos contra los indígenas para velar

${ }^{2}$ Cordero Fernández, Macarena. Naturaleza juridica de las visitas de idolatrías. Lima. Siglo XVII, en Retamal Avila, Julio, (compilador), Estudios coloniales (Santiago, Universidad Andrés Bello, 2006), IV; LA MISMA, Formación de una institución: las visitas de idolatrías, en ZaBALla, Ana de (editora), Los indios, el Derecho canónico y la justicia eclesiástica en la América virreinal (Madrid, Iberoamericana Vervuert, 2011).

${ }^{3}$ Antes que en España se organizara el Santo Oficio de manera estructurada y orgánica, con asientos de tribunales permanentes, y presidido por la Suprema, los tribunales inquisitoriales eran ambulantes o itinerantes. Viajaban por el territorio en compañía de todos los funcionarios. Por efecto de la sedentarización del Santo Oficio de la Inquisición, escaparon al control religioso una serie de localidades rurales. Frente a ello, se organizaron las llamadas visitas de distrito inquisitoriales con la finalidad de estrechar la vigilancia sobre las posibles desviaciones de la fe cometidas en zonas donde no llegase la acción de él. Con esta medida entonces se paliaba la ausencia del organismo permanente. Tales visitas eran dirigidas desde un centro fijo o asiento de tribunal; se llevaban a efecto generalmente una vez al año y tenían por misión inspeccionar distintos distritos, abarcando muchas veces varios obispados. La visita tenía una duración variable, era conducida por un visitador, un notario y un alguacil, quienes iniciaban procesos de rápida tramitación. Durante la visita, el séquito recibía las denuncias y tomaba los testimonios que debían presentarse al tribunal. Es decir, las facultades que conllevaban estas visitas se limitaban a investigar la existencia de conductas heréticas para luego remitirlas al tribunal, el que finalmente conocía y fallaba el delito. Todo, sin perjuicio de que los casos de menor importancia podían ser resueltos in actum. Por ello, estos visitadores no hacían detenciones, salvo ante peligro de evasión. Estas visitas fueron base para la organización de las visitas de idolatrías. Véase: LEA, Charles, Historia de la Inquisición española. (Madrid, Fundación Universitaria Española, 1983), II, pp. 66 y 96; Kamen, Henri, La Inquisición española. (Barcelona, Editorial Crítica, 2004), p. 176; Dedieu, Jean Pierre, Les inquisiteurs de Toledo et la visite du district, en Mélanges de la casa de Velásquez, XIII (1977); Millar, René, Inquisición y sociedad en el virreinato peruano (Santiago, Pontificia Universidad Católica de Chile, 1997), p. 42. 
por sus espacios de poder, y por otra, un incipiente cuestionamiento al sistema y doctrina del Antiguo Régimen, originando un sistema de justicia que es posible de calificar de protomodernizante.

\section{REFORMULACIÓN DE LOS PROCEDIMIENTOS DIRIGIDOS A LOS INDÍGENAS A PARTir del Estatuto Protector}

La pervivencia de las idolatrías en la diócesis limeña se decidió resolver mediante la estrategia judicial, organizándose para ello las visitas de idolatrías que velaban por la ortodoxia religiosa, cuyo modelo principal fue la Inquisición Española aunque reformulada a base de la realidad andina. En este contexto, lo que de manera sustancial le dio fisonomía original a esta nueva institución, y por ende la diferenció de la Inquisición, fue sin duda el estatuto jurídico que protegía al mundo indígena. En efecto, sabemos que los indios fueron considerados por la Corona como vasallos de la misma; por lo tanto, personas o sujetos de derecho que gozaban de absoluta libertad. Sin embargo, por sus condiciones culturales, que se interpretaban como falta de capacidad y escaso conocimiento, fueron asimilados a la categoría de miserables o rústicos de Castilla, lo que significó que requirieran de especial protección. Dicho de otro modo, la condición de miserables implicó entender que los indígenas no podían valerse o defenderse por sí mismos, y que por lo tanto las autoridades tenían la obligación de protegerlos y ayudarlos ${ }^{4}$.

Por lo anterior, la condición de miserables de los indígenas no se estableció debido a su pobreza material, sino más bien a que fueron considerados incapaces de alcanzar por sí mismos el bien común, y por lo tanto, la salvación eterna. Tal posición de desamparo de los indígenas conllevó una responsabilidad para todo el cuerpo social, que debía acoger, proteger, ayudar y ejercer correctamente la justicia hacia ellos, con la finalidad de conducirlos armónicamente al sistema cultural hispano. En otras palabras, la condición de miserables de los indígenas implicó que el estatuto jurídico protector asociado a ella debía ser acatado por todas las instituciones y personas. En definitiva, que la comunidad toda debía amparar los derechos de sus personas y bienes 5 .

Lo anterior se tradujo en que los procedimientos utilizados por la Inquisición, modelo de las visitas de extirpación aplicadas en Lima, se vieron reformulados por las especiales características etnográficas, sociales y culturales de la población indígena de estos territorios. En efecto, conforme a los principios generales consagrados en la legislación de Indias, los indios debían ser protegidos de posibles injusticias y falsas acusaciones. Ello se complementaba con la obligación de dar publicidad a los actos y actuaciones judiciales en los que interviniera un indígena. Así pues, de todas las instituciones y normativas relativas al mundo indígena es posible

\footnotetext{
${ }^{4}$ Castañeda, Paulino. La condición miserable del indio y sus privilegios, en Anuarios de Estudios Americanos, 28 (Sevilla, 1971), p. 248.

${ }^{5}$ Para más detalles, véase: Dougnac, Antonio. Manual de Historia del Derecho indiano (México, UnAm, 1994), p. 315. BRuno, Cayetano, El Derecho público de la Iglesia en las Indias (Salamanca, Consejo Superior de Investigaciones Científicas - Instituto San Raimundo de Peñafort, 1967), p. 23; Castañeda, Paulino, cit. (n. 4).
} 
desprender que están presentes estos principios inspiradores y rectores, cuestión que se traduce, por ejemplo, en la imposibilidad de poder aplicar el secreto como principio rector de los procedimientos, tanto reales como inquisitoriales.

Lo expuesto cobra una real importancia, puesto que la bula de Inocencio IV, que reguló el procedimiento judicial seguido por la Inquisición, ordenaba a los frailes predicadores, inquisidores pontificios y obispos mantener en secreto los nombres de los acusadores y testigos que actuaran en los procesos inquisitoriales ${ }^{6}$. Sin embargo, en el caso de las visitas de extirpación sí se permitió a los indígenas acusados conocer la identidad, tanto de los testigos como de quienes los incriminaban, cuestión verdaderamente fundamental y revolucionaria del procedimiento inquisitivo. Piénsese que en el plenario del procedimiento inquisitorial del Santo Oficio: “[...] el reo tenía derecho a tachar a aquellas personas que consideraba enemigos y si alguno de ellos estaba entre los testigos su testimonio no podía ser tomado en cuenta. Sin embargo, como el reo y su abogado desconocían nombres de los que habían testificado, actuaban siempre por conjetura a la hora de indicar las tachas; además, según las Instrucciones y manuales, el acusado debía probar la calificación de enemigo de la persona que tachaba"

Esto evidentemente entorpecía y dificultaba en demasía la defensa del reo. $\mathrm{Al}$ contrario, en los procesos llevados adelante contra los indígenas de las zonas rurales de la diócesis de Lima, a éstos no sólo se les permitió conocer a quienes los denunciaban o testificaban en su contra, sino que además, podían tacharlos en cualquier tiempo (desde que tenían conocimiento de sus identidades). Además, se les permitía agregar retrospectivamente nuevos nombres a la lista de enemigos, respetándose de esta manera la normativa procesal favoreciente a los nativos ${ }^{8}$. Así, en la causa seguida contra el curaca y gobernador Leandro Poma Chagua, el acusado solicitó que comparecieran ante el tribunal el cura doctrinero Luis de Villavicencio, querellante, y todos los demás testigos presentados en su contra, puesto que el cura doctrinero se había querellado en venganza y obligado a todos los indios a dar testimonios falsos. Aquí, el acusado conocía el nombre de su denunciante y de todos los testigos. Más aún, solicitó que fuese tachado en razón de los conflictos que tenía con el cura?

Como dijimos, esto constituye una novedad del procedimiento en cuestión y una reforma del mismo, puesto que deja atrás uno de los principios del sistema

${ }^{6}$ Inocencio IV, bula dada en Letrán, 1254, en Martínez Díez, Gonzalo, Bulario de la inquisición española. (Madrid, Editorial Complutense, 1998), p. 25: "Queremos ciertamente que los nombres tanto de los que acusan la pravedad de los herejes como lo de los testigos en dichas acusaciones no se hagan públicos, por el escándalo y el peligro que puede seguirse de tal publicación $[\ldots] "$.

${ }^{7}$ Millar, René, cit. (n. 3), p. 51.

${ }^{8}$ Solórzano y Pereyra, Juan, Politica indiana lib. II, cap. 28을 número 25 (Madrid, Biblioteca de Autores Españoles, 1972).

${ }^{9}$ Archivo Arzobispal de Lima (en adelante AAL), legajo V, exp. 13, "Caussa criminal contra el maestro de campo don Leandro Poma Chagua governador de sinco repartimientos fautor de hechisseros y consentidor de amanssebados y fasinerosos por querella del lissençiado don Luis de Villaviessençio cura de la doctrina de Pachas", fs. 38. 
inquisitorial llevado adelante por el Santo Oficio: el secreto ${ }^{10}$. En efecto, las visitas de extirpación de idolatrías, que se inspiraron en la Inquisición, adecuaron sus normas a las especiales circunstancias del mundo indígena. Por una parte, conforme al estatuto jurídico de los indígenas, éstos debían ser protegidos precisamente de injusticias y falsas acusaciones, cuestión que no se cumpliría de haberse mantenido el secreto, pues habrían carecido de una legítima defensa. Por otra, se fue configurando un procedimiento precursor del modernismo procesal en el sentido de ir desarrollando un debido proceso, situación que no se va a establecer para los españoles y criollos si no muchos años después, en razón de la transformación que sufriría el derecho procesal y penal a partir del siglo XVIII y por influencia de la Ilustración.

Más aún, desde el decreto de Inocencio III Vergentis in senium, de 1199, dirigido al pueblo de Viterbo, se establecía: "Si a los culpables del delito de laesae maiestatis,_castigados según las penas legales con la muerte, se les confiscan sus bienes, perdonándose la vida de sus hijos por pura misericordia, cuanto más aquellos que alejándose de la fe en el Señor ofenden a Jesucristo, hijo de Dios, deben ser por sentencia eclesiástica separados de nuestra cabeza, que es Cristo [...] pues es mucho más grave delinquir contra la majestad eterna que contra la temporal' ${ }^{11}$.

En este punto, las visitas de extirpación se alejaron de la Inquisición en cuanto a que si bien el delito de idolatría se asimiló al de lesa majestad, no es menos cierto que se hizo imposible la aplicación de la máxima pena del orden temporal. Esta sanción consistía en la entrega del culpable al brazo secular para su relajación (pena de muerte). En razón de la especial protección de la Corona al mundo aborigen, se impidió aplicar la pena de muerte a los indios que se alejaren de la ortodoxia, toda vez que se entendió que éstos eran nuevos en la fe católica. Así, se hacía difícil que tuvieran el mismo grado de conocimiento, profundidad y fe que el de otros habitantes indianos ${ }^{12}$.

No obstante, la restricción de aplicación de penas no se limitó solamente a la relajación. Recordemos que la legislación especial para los indígenas contemplaba que cualquier delito cometido por un nativo tendría una sanción rebajada en dos o más grados en relación a si el mismo delito lo hubiese cometido un español o un criollo ${ }^{13}$.

Este criterio también se ve en los expedientes de idolatría, pues en ellos es posible apreciar cómo respecto de determinadas conductas merecieron penas

\footnotetext{
${ }^{10}$ Lea, Henry, cit. (n. 3), II, p. 364; Kamen, Henri, cit. (n. 3), p. 79.

${ }^{11}$ Inocencio III, Litterae Decretales (1199), en Martínez Díez, Gonzalo, cit. (n. 6), p. 9.

${ }^{12}$ Luego de ser relajado por el brazo secular el cacique don Carlos por idólatra, bajo el obispado de Zumárraga en Nueva España, la Corona no sólo excluyó de la jurisdicción del Santo Oficio a los naturales, sino que impidió la aplicación de la pena de muerte por delitos contra la fe. Medina, Toribio. La primitiva inquisición americana. 1493-1569 (Santiago de Chile, Imprenta Elzeviriana, 1914), p.142.

${ }^{13}$ Recopilación de Leyes de Indias. lib. VI, tít. $10^{\circ}$, ley $21^{\mathrm{a}}$ : "[...] ordenamos y mandamos que sean castigados con mayor rigor los españoles que injurieren u ofendieren o maltrataren a indios que si los mismos delitos se cometiesen contra españoles y los declaramos por delitos públicos [...]".
} 
diversas, ya sea si fueron impuestas por los visitadores de idolatrías o bien por la justicia eclesiástica ordinaria ${ }^{14}$.

Otro de los privilegios de los nativos lo encontramos en la tramitación misma de los juicios. Estos debían ser breves y sumarios, tanto para asuntos civiles como para criminales y eclesiásticos. Con ello se quería evitar las grandes dilaciones que se presentaban en los tribunales que operaron en las Indias. En el caso de los procedimientos de extirpación, sorprende que éstos hayan sido llevados a cabo en breves lapsos de tiempo, cuando los comparamos con los procesos seguidos por el Santo Oficio, más aún cuando en estos últimos primaba el principio de "cambio de ritmo procesal, esto es la posibilidad, siempre en manos del tribunal, de acelerar o retrasar casi indefinidamente el ritmo de las actuaciones procesales"15.

La respuesta a lo anterior no solamente se debe encontrar en el hecho de que eran tribunales itinerantes, con un tiempo determinado para visitar varias localidades, sino también en que los gestores del sistema tuvieron presente la normativa dirigida a proteger a los indios. En efecto, si contrastamos las visitas de idolatrías con las visitas de distritos o con las visitas pastorales, podemos apreciar que los procedimientos llevados a cabo por todas ellas eran de carácter breve y sumario. Sin embargo, las visitas de distritos y las visitas pastorales tenían por objeto investigar, para luego remitir los autos al tribunal u obispo, quien concluía el asunto. Incluso, si era el obispo quien personalmente realizaba la visita pastoral, le estaba impedido pronunciar sentencias y decretar penas ${ }^{16}$. Al contrario, las causas seguidas por los visitadores se tramitaron breve y sumariamente, incluyendo el fallo o sentencia de la misma.

Aún más, el estatuto protector indígena contemplaba la obligación de que los indios en todo tipo de procesos debían contar con un defensor. En el caso de las visitas de idolatrías se contempló un sistema especial de defensas que consistía en que un miembro del séquito extirpador hacía las veces de "abogado". Con todo, los protectores de naturales en atención a las atribuciones que les concedía el ordenamiento jurídico, decididamente optaron por intervenir en los procesos contra las idolatrías provocando -como ya lo veremos- debates y fisuras al orden establecido en el Antiguo Régimen.

En buenas cuentas, el mecanismo concebido por la legislación canónica indiana para lograr la unidad e integridad de la fe frente a las idolatrías era la aplicación del procedimiento inquisitorial, pues las idolatrías se enmarcan dentro de los delitos que atentaban contra la ortodoxia. Sin embargo, era imposible aplicarlo al mundo indígena tal cual estaba contemplado, ya que habría contravenido precisamente el estatuto jurídico que protegía y amparaba a los indios.

\footnotetext{
${ }^{14}$ Cordero Fernández, Macarena, Las penas y los castigos para la idolatría aplicados en las visitas de idolatría en Lima durante el siglo XVII, en Revista de Estudios Históricos-Jurídicos, 32 (Valparaíso, 2010), pp. 351-379.

15 Tomás y Valiente, Francisco, Relación de la Inquisición con el aparato institucional del Estado, en Gobierno e instituciones en la España del Antiguo régimen (Madrid, Alianza Editorial, 1982), p. 34.

${ }^{16}$ Concilio de Trento, sesión 24a , en Donoso, Justo, Instituciones del Derecho canónico americano (Paris, Librería de Rosa y Bouret, 1858), p. 334.
} 
Por lo anterior, es que el sistema de extirpación creado en 1609 bajo el arzobispado de Bartolomé Lobo Guerrero, apoyado por el virrey y la Compañía de Jesús en la diócesis de Lima, que se extendió a lo largo de todo el siglo XVII, es una institución propia del derecho canónico indiano. Se gestó de las especiales circunstancias de la realidad americana en combinación con la tradición y las instituciones españolas. Dicho de otro modo, la obligación de estructurar esta institución respetando el estatuto que protegía al mundo indígena, transformó el sistema y modelo diseñado por el derecho canónico.

Así, y como ya se ha señalado, no fue posible aplicar el sistema inquisitorial tal como estaba definido, porque habría entrado en contravención con todas las normas protectoras de los indígenas. Se debió en definitiva modificar y adecuar a la propia realidad americana, dando origen así a una nueva institución en las Indias, que debió observar la obligación de respetar el estatuto jurídico del estamento indígena y contar con el apoyo expreso del poder regio a través de los mecanismos legales que contemplaba el ordenamiento jurídico de la época, manifestado en la autorización de las normas conciliares y sinodales.

\section{Abogados DEFEnSORES}

Pues bien, al igual que la Inquisición Española, al tiempo de realizarse la acusación por parte del fiscal, se contemplaba por la legislación canónica indiana penal que debía nombrarse un defensor para el o los acusados en la causa contra las idolatrías, diferenciándose así de la Inquisición Medieval, la cual no permitió, en sus primeros siglos de funcionamiento, la participación de abogados, procuradores o defensores en la defensa de los herejes ${ }^{17}$. Así: "Hechas las informaciones los que resultaren culpados seran presos en carcel segura, y se tomaran sus confesiones a cada uno de por si, nombrandoles para ello defensor que este presente [...]"18.

No obstante, en la Inquisición Española el abogado era un funcionario designado por el Tribunal, que se encontraba en una nómina según la cual estaba especialmente autorizado para realizar la defensa. Es más, como el abogado era un funcionario del tribunal, trabajaba plenamente de acuerdo con el inquisidor, puesto que el principal objetivo que tenía era coadyuvar a que el reo confesara sus herejías ${ }^{19}$.

Por su parte, la institucionalidad de las visitas de idolatrías contempló que los indígenas tuvieran abogados o defensores si eran sometidos a proceso por actos idolátricos, pudiendo recaer el cargo en un miembro del séquito ${ }^{20}$. En otras palabras, el procedimiento de las visitas de idolatrías en este punto siguió las normas estatuidas por la Inquisición, que mantenía una nómina de abogados a la cual se debía recurrir en caso de ser acusado de herejías. En efecto, quienes eran declara-

\footnotetext{
${ }^{17}$ Clavasio, Angeli de, Summa Angelica, S. VII Haereticus, 20, citado por Lea, Henry, cit. (n. 3), II, p. 546.

${ }^{18}$ Villagómez, Pedro de, Carta Pastoral de exhortación e instrucción acerca de la idolatría de los indios del arzobispado de Lima, (Lima, 1647), p. $67 \mathrm{vta}$.

${ }^{19}$ LEA, Henry, vit. (n. 3), II, p. 546.

${ }^{20}$ Villagómez, Pedro de, cit. (n. 18), p. 67 vta.
} 
dos reos por la Inquisición sólo podían defenderse mediante los abogados que la propia institución señalaba, cuestión que claramente conllevaba una arbitrariedad, puesto que dichos abogados no necesariamente llenaban las expectativas de sus defendidos. Con todo, era la única esperanza de una defensa para los acusados. De manera equivalente, en el caso de las visitas, el hecho de contemplar entre sus miembros un defensor para los indígenas, podía prestarse para abusos, pues se podía razonablemente suponer que este funcionario realizaba más funciones de coadyuvante del visitador, que ser una real defensa para el reo.

Ahora bien, pese a que el contemplar defensas para los reos es una similitud entre la Inquisición y las visitas de idolatrías, los motivos que se tuvieron para considerarlas distancian a ambas instituciones. En efecto, conforme al estatuto jurídico de los indígenas, éstos siempre debían contar con defensores para todo tipo de procesos, pues se podían ver expuestos a abusos, precisamente porque no hablaban el castellano y no conocían los procedimientos. Incluso se contemplaron tribunales especiales donde eran ventilados los juicios en que participaban los indios.

Por lo anterior, al iniciarse el proceso de regulación del sistema de visitas de idolatrías, la Iglesia no olvidó que si los indios no contaban con defensores, sus juicios podían ser declarados nulos, puesto que contravenían la legislación real. De ahí que el defensor era nombrado, aun cuando el acusado estuviese confeso de sus delitos, generalmente en la etapa acusatoria.

Este defensor era las más de las veces un integrante del séquito extirpador, sin perjuicio que hubo causas en que los sacerdotes doctrineros fueron designados por el visitador como defensores ${ }^{21}$. Asimismo, aunque con carácter excepcional, la defensa podía recaer en un indígena, como fue en el caso de Cristóbal Carua Naupa ${ }^{22}$, lo que era posible dado al carácter especial del procedimiento pues estaba dirigido contra los indígenas, los que contaban con un estatuto personal que los protegía. Si bien podría ser un contrasentido que un cacique u otro indígena defendiera a sus pares, ello no fue tal, precisamente porque estamos en presencia de procedimientos con menores formalidades, los que a su vez contaban con mayores garantías a favor de los indígenas. Ejemplo de ello, fue la posibilidad de conocer la identidad de los testigos.

Sumado a lo anterior, señalemos que no es de extrañar que los propios indígenas hiciesen las veces de defensores, puesto que muchos de ellos, especialmente los indios ladinos, fueron auxiliares de los séquitos extirpadores, realizando labores de fiscales, intérpretes, alguaciles, entre otras. Además, ello refleja que para esta época muchos indígenas se habían reapropiado de la estructura judicial hispana realizando labores de "abogados" o representantes de los reos. A su vez, denota que los indígenas, pese a su condición jurídica de "miserables", comprendían el funcionamiento de los procesos judiciales. En otras palabras, los indios utilizaban y reconocían el ámbito judicial no sólo como un espacio de reclamos y de argu-

${ }^{21}$ AAL., leg. I, exp. 6: "Causa criminal de hechicero de oficio seguida contra Cristóbal Curis Anapa, indio ciego, natural de Huañec, 1621".

${ }^{22}$ AAL., leg. I, exp. 6: "Causa criminal de hechicero de oficio seguida contra Cristóbal Curis Anapa, indio ciego, natural de Huañec, 1621”. 
mentación para ellos ${ }^{23}$, sino también como espacio para coadyuvar en la tarea de juzgar, fuese como fiscales, alguaciles o demás miembros del séquito, así como en la defensa de otros indígenas.

Consecuencia de lo expuesto es que no se requería de un abogado o de una persona con conocimientos técnicos del Derecho para realizar la defensa en primera instancia ${ }^{24}$. Bastaba con que fuese alguien capaz de poder representar a otro en el proceso y comprender de qué manera funcionaba el sistema. Por lo demás, en las causas de idolatrías se permitió que quien defendiera a un indígena conociera todas las actuaciones efectuadas en el proceso, con lo cual podía realizar una mejor defensa, a diferencia de lo que ocurría en la Inquisición, en la que si bien el reo era defendido por un letrado, éste sólo podía acceder a una copia de la publicación de pruebas, que era muy distinta de las declaraciones originales, lo que limitaba una debida defensa.

Más aún, probablemente la defensa dirigida por un indígena podía tener un grado de mayor imparcialidad. Ello porque, conforme a los expedientes analizados, en algunos casos el cargo de defensor no recayó en un miembro del séquito extirpador, sino en un indio principal de un pueblo, que como tal no estaba comprometido o vinculado al tribunal, garantizando, de esta forma, mayor ecuanimidad a la hora de desvirtuar los cargos.

Ahora bien, la tarea del defensor consistía en realizar las solicitudes, peticiones, presentaciones de escrito y cuanta gestión fuese necesaria para la defensa del acusado en su nombre y representación. Para cumplir dichas labores, era el visitador de idolatrías, mediante resolución judicial, quien designaba al abogado defensor del acusado. Tal nombramiento era notificado personalmente, con el fin de que en ese momento el designado jurase aceptar auxiliar lealmente al acusado, realizar la defensa y actuar en justicia.

Actuar en justicia significaba que la misión del abogado era no sólo defender mediante la desvirtuación de los cargos, sino que implicaba, además, descubrir si el reo era o no culpable, de tal manera que si el reo era inocente, el defensor debía realizar todo aquello para que fuese declarado como tal. No obstante, en caso contrario, es decir, si era culpable, la labor del defensor apuntaba a obtener que su defendido se declarara culpable, confesara y se arrepintiera ${ }^{25}$.

${ }^{23}$ En tal sentido: ArayA, Alejandra. La función de la memoria colonial: la construcción de sujetos y narrativas en el espacio judicial del siglo XVIII, en Cornejo, Tomás - GonZÁlEZ, Carolina, Justicia, poder y sociedad en Chile: Recorridos históricos (Santiago, Ediciones Universidad Diego Portales, 2007), p. 193.

${ }^{24}$ Los procuradores de naturales conforme cédulas de 1591 y 1614 , contenidas en la $R e$ copilación de leyes de Indias, tenían como función proteger a los indígenas frente eventuales abusos, y si eran letrados, podían litigar en primera instancia por ellos. En las visitas de idolatrías, se autorizó la posibilidad de que personas no letradas realizaran la defensa, precisamente porque se trató de procedimientos con menos formalidades, que asimismo contenían mayores garantías para los indígenas. Por lo demás las Partidas III,6,2 contemplaban que podía realizar las funciones de abogado: "todo hombre que fuere sabedor de derecho o del fuero o de las costumbres de la tierra porque lo haya usado de gran tiempo [...]". Con todo, en el tribunal de alzada siempre fueron defendidos los indios por abogados letrados.

${ }^{25}$ Villagómez, Pedro de, cit. (n. 18), p. 67-67 vta. 
Así pues, de cierta manera, la tarea del defensor implicaba más coadyuvar al tribunal que realizar una efectiva defensa del acusado, lo que se debía, en parte, a que el defensor generalmente era un miembro del séquito extirpador, y como tal, debía dar cumplimiento al objetivo del tribunal: extirpar idolatrías.

Seguidamente, porque tras las causas de idolatrías se estaba protegiendo el principal bien jurídico de la época, la fe libre de herejías; bien que debía ser amparado por todos los súbditos de la Corona. En tal sentido, la función del defensor era velar por que se cumpliese con dicho mandato, debiendo, por tanto, colaborar en la mantención del catolicismo.

Con todo, como los acusados en estas causas eran indígenas, se produjeron modificaciones sustanciales respecto de lo que acontecía en la Inquisición Española. Prueba de ello es que en varios expedientes de extirpación vemos la activa participación del protector de naturales, funcionario especialmente creado para el amparo de los indios, que en muchas oportunidades intervino en estas causas defendiendo de manera incansable a los indígenas y sus derechos especiales contemplados en las leyes indianas ${ }^{26}$.

Así pues, y como lo hemos comentado, el cargo de defensor recaía generalmente en un miembro del séquito. Tal situación fue puesta en tela de juicio por los protectores de los naturales, que vieron en dichos nombramientos una vulneración al estatuto protector de los indios. Recordemos que el procedimiento de las visitas de idolatrías en este punto siguió las normas contempladas por el derecho canónico a propósito de las visitas de distrito, e incluso del Santo Oficio que mantenía una nómina de abogados a la cual se debía recurrir en caso de ser acusado de herejías. En efecto, quienes eran declarados reos por la Inquisición sólo podían defenderse mediante los abogados que la propia Institución señalaba, lo que claramente conllevaba una arbitrariedad, puesto que dichos abogados no necesariamente llenaban las expectativas de sus defendidos. Con todo, era la única alternativa de una defensa para los acusados.

En el caso del mundo indígena, los protectores de naturales consideraron poco objetivas y efectivas las defensas cuando recaían en un miembro del séquito. Por ello es que interpusieron recursos de nulidad, los que fueron fallados adversamente a sus pretensiones. No obstante, es posible deducir de estos hechos que los defensores, en general, eran funcionarios del tribunal y que, como tales, estaban más interesados en extirpar las idolatrías que en defender a los acusados, produciéndose, en ocasiones, situaciones injustas. Seguidamente, que existía un grado de conciencia de parte de la institución de protectores de naturales según la cual se debía velar por los derechos de los indígenas no sólo en materias civiles reguladas por la Corona, sino que también frente a los séquitos extirpadores que se regían por el derecho canónico indiano, el que, según el juicio de los protectores, vulneraba el estatuto protector de los indios al designar un defensor de entre sus propios miembros. A su vez, es posible interpretar esto como una estrategia de parte de los Protectores para conservar sus esferas de poder, que se veían vulneradas

\footnotetext{
${ }^{26}$ Recopilación de leyes de Indias lib. VI, tit. $5^{\circ}$. Para más detalles véase: BaYLE, Constantino, El protector de indios (Sevilla, 1945); CutTER, Charles R, The "Protector de Indios" in Colonial New Mexico, 1659-1821 (University of New Mexico Press, 1986).
} 
y tambaleantes ante la presencia de los defensores miembros del séquito e incluso de aquellos indígenas que presentaron defensas.

Por otra parte, tal situación denota el cambio de criterio que se estaba gestando a propósito del mundo indígena en el Derecho Canónico Procesal, como también en el Derecho Real. En efecto, tras la idea de garantizar a los indígenas sus derechos fundados en su escasa capacidad, los juristas, filósofos y teólogos de la época debieron reformular muchas de las instituciones jurídicas que regían desde hacía mucho en el mundo occidental, debiendo establecer garantías mínimas que defendiesen y amparasen a los indios. Garantías que eran impensadas hasta ese entonces para otros estamentos del mundo hispano indiano y occidental, que solo empezarán a ser reformuladas a partir del siglo XVIII, mediante el concepto del debido proceso.

Se manifiesta, entonces, en los expedientes de idolatrías una tensión y discontinuidad entre las prácticas judiciales tradicionales y la penetración paulatina de elementos que pretenden precisamente transformar la hegemonía del discurso judicial en pos de nuevos o alternativos discursos, fruto de los cambios de creencias y sensibilidad que progresivamente se impondrán en la sociedad occidental, y que dejarán atrás el antiguo orden judicial, político y social ${ }^{27}$. Dicho de otro modo, las reclamaciones realizadas por los protectores de naturales pueden ser consideradas como rupturas del sistema judicial imperante en la época. Ello porque las prácticas judiciales son vistas como antagónicas a las reformulaciones que se están articulando progresivamente por diversos actores de la sociedad colonial ${ }^{28}$.

A su vez, es posible sostener que los protectores de naturales, figuras constituidas por la Corona especialmente para que representaran a los nativos en foros judiciales y en materias jurídicas extrajudiciales, a lo menos en cuanto a las idolatrías, ampliaron y reformularon dicha representación, puesto que se convirtieron en portavoces de las opiniones de quienes no podían enunciarlas por sí mismos. De este modo hicieron visible en el espacio judicial, entorno en que podían desenvolverse, las rupturas a las prácticas judiciales socialmente aceptadas ${ }^{29}$.

Asimismo, las obligaciones y deberes de los defensores de los indígenas se debían dirigir siempre y sin excepción a la idea de asegurar los derechos de éstos. Lo que por lo demás involucraba un mayor grado de independencia.

Y así lo entendió el procurador de los naturales Thomas Hurtado, quien presentó un recurso de nulidad contra un fallo emitido por el visitador de idolatrías Bernardo de Noboa. Si bien estaba plenamente permitido que un miembro del séquito fuese el defensor, lo cierto es que a ojos de los protectores de naturales era visto como un subalterno del visitador, hecho que en definitiva dejaba sin una justa

\footnotetext{
${ }^{27}$ El que estas prácticas precursoras de la modernidad sean aisladas o dispersas entre sí no les resta legitimidad, y por ende, pueden ser consideradas legítimamente como las que dan origen a un nuevo orden o interpretación al orden judicial. En sentido similar, CHARTIER, Roger, Espacio público, critica y desacralización en el siglo XVIII (Barcelona, Gedisa Editorial, 2003).

${ }^{28}$ Foucault,. Michel. La verdad y las formas jurídica (Barcelona, Gedisa, 2003).

${ }^{29}$ Habermas, Jurgen. Historia crítica de la opinión pública (Barcelona, Gustavo Gili, 1999), p. 46-47.
} 
defensa al indígena. Es decir, los protectores de naturales pusieron en tela de juicio las defensas de los abogados defensores miembros del séquito: "Consta lo mismo y biste de notoria injusticia la dich a nulidad hallarse los dichos mis partes yndefensos sin que por ellos se hiçiese diligençia alguna pues aunque Domingo Mautino se nombro por su defensor el susodicho que hera persona dependiente del dicho Juez Visitador y abecindado en su doctrina no hiço mas defensa que decir estaban los dichos mis partes conbictos y confiesos sin haçer distinción de personas ni ynterponer suplicaçion de la sentençia que se pronuncio la qual se executo [...]"30.

Si bien los recursos presentados en este sentido para anular los juicios no prosperaron, y se estableció que los miembros del séquito estaban absolutamente capacitados para realizar defensas, la verdad es que vislumbramos básicamente la idea de debido proceso y la existencia de debates respecto del rol que efectivamente debían jugar los defensores y abogados de aquellos más desvalidos, los indígenas.

En efecto, el recurso de nulidad antes comentado alude a que en realidad no hubo defensa, puesto que quien cumplió tal función era un miembro del séquito. Para los protectores de indios, especialmente llamados a proteger a los indígenas frente a los eventuales abusos, esto era una situación inaceptable, pues consideraban que se vulneraba el derecho a protección que tenía este grupo indiano. Dicho de otro modo, se puso en tela de juicio la función de coadyuvante que tenían estos funcionarios.

En buenas cuentas, tras estos incipientes debates estaba la idea de que si los indios iban a ser sometidos a proceso por las autoridades indianas, lo mínimo era que hubiera posibilidades reales de defensa.

Lo anterior nos explica por qué en una serie de causas de idolatrías los protectores de naturales empezaron ya no sólo a patrocinar las apelaciones en Lima ante el Arzobispo ${ }^{31}$, sino que intervinieron directamente en la primera instancia, realizando ellos las defensas de los reos, y no un miembro del séquito ${ }^{32}$.

Así, en la causa seguida contra Juana de Mayo, rea confesa, a quien se le acusaba de la realización de hechizos, adivinar el futuro, idolatrar y haber huido de la cárcel, se logró, gracias a la labor del protector de los naturales, Bernardo de

${ }^{30}$ AAL. leg. III. exp. 11: "Denuncia que hace don Juan Tocas principal y fiscal de la dicha visita contra Hernando Hacas Cristóbal Poma Libiac y muchos indios del pueblo de San Pedro de Hacas".

${ }^{31}$ AAL., leg. V, exp. 5: "Apelación seguida por el procurador de los naturales para que Maria Gomez, india de Haumatanga, sea sacada de la prision por estar muy enferma, debido a los maltratos recibidos por el visitador Juan Sarmiento de Vivero, 1664".

${ }^{32}$ La visita de idolatría fue una institución canónica indiana respaldada por la Corona. En su proceso de formación, regulación e institucionalización no se contempló la participación de los protectores de naturales. Ello respondió al hecho de que la Iglesia peruana al crear estos tribunales consideró que se cumplía con el estatuto protector de los nativos con la inclusión de defensores. Por lo demás, como se trataba de una institución canónica, sus organizadores siguieron de cerca la Inquisición, la que también tenía una nómina de abogados propios. Pues bien, es interesante constatar que los protectores de naturales, por su propia iniciativa, decidieron participar activamente en las visitas de idolatrías reformulando y criticando el rol que les cabía a los defensores de la nómina del tribunal en pro de una debida defensa. 
Acuña, una pena bastante inferior respecto de otros casos semejantes. Más aún si tomamos en consideración que el visitador de idolatrías en este proceso era el eficiente y polémico Juan Sarmiento de Vivero ${ }^{33}$.

Finalmente, debemos establecer que si bien los defensores de los nativos en las causas de idolatrías generalmente fueron los abogados o defensores del séquito extirpador, con todo, si el tribunal no contaba con estos funcionarios, podían ejercer dicho cargo indígenas ladinos ${ }^{34}$, el cura doctrinero ${ }^{35}$ o algún español ${ }^{36} \mathrm{de}$ la confianza del sospechoso de idolatrías. Ello deja de manifiesto que los idólatras contaron con mayores opciones a la hora de ser defendidos, pudiendo elegir entre los ya indicados.

A su vez, se puede concluir que no era necesario que quienes defendieran a los reos fuesen doctos en derecho. Sin embargo, esto también fue puesto en tela de juicio por los protectores de naturales, quienes consideraban que los sospechosos de idolatrías, al no ser defendidos por agentes letrados y externos al tribunal, podían ser objeto de abusos e injusticias.

Ahora bien, una vez que el defensor asumía la defensa del acusado, el visitador de idolatrías le daba traslado y copia de la acusación, para que éste la contestase en un plazo de dos días.

A diferencia de lo que ocurría en los autos seguidos ante la Inquisición española, el defensor en las visitas de idolatrías tenía acceso a todo el expediente, con lo cual la desvirtuación de los cargos que se imputaban al acusado podía ser más efectiva. En buenas cuentas, el indígena enfrentaba un procedimiento más ecuánime e imparcial que el que enfrentaban los españoles ante el Tribunal Inquisitorial.

\section{REFLEXIONES FINALES}

La institucionalización de un sistema de justicia específico para erradicar las idolatrías en la diócesis de Lima implicó la imposición de una identidad única no sólo a partir de la religión o la lengua, sino también a base del aparato judicial. Dicho de otro modo, se trató de homogeneizar, uniformar y reglamentar el universo simbólico de los indígenas mediante, por una parte, la religión católica, elemento que constituiría el identitario con los conquistadores puesto que erradicaría sus propias singularidades culturales e históricas. De ahí que mediante diversos mecanismos se inició la etapa de evangelización y conversión de los indígenas, los que a su vez adaptaron y reformularon la religión católica a partir de sus propias cosmovisiones, produciéndose un catolicismo "local” que fue entendido, las más

${ }^{33}$ AAL., leg. VI. exp. 8, 1668. Otro ejemplo de intervención de protectores de naturales: AAL., leg. VII, exp. 15: "Causa seguida contra Diego Chauca, acusado de hechicero y curandero".

${ }^{34}$ AAL., leg. I, exp. 5: "Causa criminal de hechicero seguida contra Juan Caxa Atoc, curaca de Ullucmayo".

${ }^{35}$ AAL., leg. IV, exp. 12: "Causa criminal de hechicería de oficio contra Isabel Suyo Culqui, india del pueblo de Santiago de Anchocalla, anejo de San Lorenço de Quinti”.

${ }^{36}$ AAL., leg. V, exp. 13: "Causa criminal contra el maestre de campo don Leandro Poma Chagua, 1667”. 
de las veces por la Iglesia, de heterodoxo e idolátrico, lo que dio pábulo para corregir y sancionar, según el caso.

Por otra parte, la identidad singular se estableció a través de las estrategias judiciales que pretendían precisamente poner fin a la pervivencia de la idolatría o a la religión "local". En efecto, las comunidades americanas contaban con sus sistemas de justicia prehispánicos, de tal manera que cada persona era juzgada conforme a la cultura a la que pertenecía. Aún más, Vitoria afirmaba que como los indios habían desarrollado sus sociedades, tenían derecho a conservar sus principios, instituciones y leyes. El límite sería la idolatría y el paganismo. Así, en el ámbito teórico y legal, los indígenas podían conservar sus sistemas de justicia prehispánicos. Ello se veía refrendado por la llamada teoría de las dos repúblicas, la de españoles e indios, que propuso una separación formal y en lo posible material, a ambas culturas organizadas con sus propias leyes, costumbres y gobierno ${ }^{37}$. Dicho de otro modo, se reconocía más de un sistema de derecho al interior del Estado Indiano. Incluso más, dentro del espacio territorial indígena, era posible juzgar a no indígenas que hubiesen cometido hechos o actos contra indígenas, lo que reforzaba a la comunidad. Sin embargo, el límite estaba cuando se tenía noticias relativas a las idolatrías o paganismo de los indígenas. En tal caso, era el sistema de justicia castellano y el eclesiástico el que juzgaba.

Si bien la materia objeto del delito era unidireccional, es decir, sólo el criterio de los colonizadores determinaba si se estaba ante una idolatría, en cuanto al procedimiento y sus implicancias, los jueces podían recurrir a al sistema procesal europeo, aunque tenían que atenerse a la cultura y costumbre de los indígenas y además al estatuto protector. Prueba de ello fue el sistema judicial aplicado por las visitas de idolatrías en la diócesis de Lima. En efecto, sus organizadores tuvieron el buen cuidado de respetar lo ordenado en el Estatuto Protector por la Corona a fin de evitar conflictos con ella o con otras autoridades virreinales.

Aún más, la introducción del sistema de justicia español al mundo americano fue adaptado y reformulado por los indígenas para resolver una serie de disputas que se desencadenaron con la Conquista en las comunidades indígenas ${ }^{38}$, es decir, tal vez el nuevo sistema dio cabida a quienes, antes de la Conquista, se vieron desfavorecidos en sus intereses ${ }^{39}$.

Los indios al adoptar y reconfigurar el sistema de justicia castellano, cuestión que se manifiesta claramente en el rol de defensores que jugaron en las visitas de idolatrías, modificaron la identidad de la justicia indígena, pues utilizaron el lenguaje jurídico hispánico al momento de administrar justicia; los procedimientos siguieron la lógica indiana pues incorporan elementos como los testigos, las

\footnotetext{
${ }^{37}$ Enciso Contreras, José, El proceso penal en los pueblos de indios durante la colonia, en Anuario Mexicano de Historia del Derecho, 18 (2006), p. 233

${ }^{38}$ Borah, Woodrow, El juzgado General de Indios en la Nueva España (México, Fondo de Cultura Económica, 1985), p. 52.

${ }^{39}$ Ruz Barrio, Miguel Ángel, El Conocimiento por parte de los indígenas de la Justicia Novohispana: el caso de Mateo Chimaltecuhtli (Cholula, siglo XVI), en Anuarios de Estudios Americanos, 66 (Sevilla., 2009) 2, p. 126
} 
inspecciones, las investigaciones, las indagatorias y las pericias ${ }^{40}$. Seguidamente, al aceptar el sistema castellano de justicia, aun modificado por sus propias categorías mentales, necesariamente debieron respetar o bien allanarse a sus decisiones.

Así, si bien la introducción del sistema judicial castellano implicó una imposición al mundo indígena alterando uno más de los elementos integradores de su identidad, con todo, al ser recepcionado y manipulado por los indígenas se validó en sus espacios comunitarios y dio origen a un sistema judicial que es posible calificarlo de mestizo.

Se trata entonces, que la formulación de un sistema judicial para extirpar las idolatrías tuvo un carácter bidireccional, que implicó el intercambio recíproco entre la cultura hispana e indígena, lo que dio como resultado una transformación de las estructuras sociales, políticas, económicas y espirituales, entre ellas la Justicia, manifestado en la reformulación de los procedimientos a partir del Estatuto Protector y en la praxis judicial que estableció un sistema normativo protomodernizante, toda vez que contempló una serie de garantías a sus destinatarios que lo acercan al moderno concepto de debido proceso, que se concretizó en las defensas realizadas por los protectores de naturales.

\section{BibLIOGRAFÍA}

AraYA, Alejandra. La función de la memoria colonial: la construcción de sujetos y narrativas en el espacio judicial del siglo XVIII, en Cornejo, Tomás - GonzÁlez, Carolina, Justicia, poder y sociedad en Chile: Recorridos históricos (Santiago, Ediciones Universidad Diego Portales, 2007).

Arriaga, Pablo de, La extirpación de las idolatrías en el Perú (Estudio preliminar y notas de Urbano, Henrique, Cusco, Centro de Estudios Regionales Andinos Bartolomé de las Casas, 1999).

BAYLE, Constantino, El protector de indios (Sevilla, 1945).

Berdeja Hurtado, Sandra Griselda, La práctica de la justicia como política de desencuentros: identidad y jurisdicción en la administración de la otra justicia, en: www. ibcperu.org/doc/isis712442.

BoraH, Woodrow, El juzgado General de Indios en la Nueva España (México, Fondo de Cultura Económica, 1985).

Bruno, Cayetano, El Derecho público de la Iglesia en las Indias (Salamanca, Consejo Superior de Investigaciones Científicas - Instituto San Raimundo de Peñafort, 1967).

Castañeda, Paulino. La condición miserable del indio y sus privilegios, en Anuarios de Estudios Americanos, 28 (Sevilla, 1971).

CHARTIER, Roger, Espacio público, crítica y desacralización en el siglo XVIII (Barcelona, Gedisa Editorial, 2003).

Cordero Fernández, Macarena, Formación de una institución: las visitas de idolatrías,

\footnotetext{
${ }^{40}$ Berdeja Hurtado, Sandra Griselda, La práctica de la justicia como política de desencuentros: identidad y jurisdicción en la administración de la otra justicia, en: www.ibcperu. org/doc/isis 712442
} 
en Zaballa, Ana de (editora), Los indios, el Derecho canónico y la justicia eclesiástica en la América virreinal (Madrid, Iberoamericana Vervuert, 2011).

Cordero Fernández, Macarena, Las penas y los castigos para la idolatría aplicados en las visitas de idolatría en Lima durante el siglo XVII, en Revista de Estudios HistóricoJurídicos, 32 (Valparaíso, 2010).

Cordero Fernández, Macarena, Naturaleza jurídica de las visitas de idolatrías. Lima. Siglo XVII, en Retamal Avila, Julio, (compilador), Estudios coloniales (Santiago, Universidad Andrés Bello, 2006), IV.

Cutter, Charles R, The "Protector de Indios" in Colonial New Mexico, 1659-1821 (University of New Mexico Press, 1986).

Dedieu, Jean Pierre, Les inquisiteurs de Toledo et la visite du district, en Mélanges de la casa de Velásquez, XIII (1977).

Donoso, Justo, Instituciones del Derecho canónico americano (Paris, Librería de Rosa y Bouret, 1858).

Dougnac, Antonio. Manual de Historia del Derecho indiano (México, unam, 1994).

EnCISO Contreras, José, El proceso penal en los pueblos de indios durante la colonia, en Anuario Mexicano de Historia del Derecho, 18 (2006).

FouCAult, Michel. La verdad y las formas jurídica (Barcelona, Gedisa, 2003).

Habermas, Jurgen. Historia crítica de la opinión pública (Barcelona, Gustavo Gili, 1999).

Kamen, Henri, La Inquisición española (Barcelona, Editorial Crítica, 2004).

LEA, Charles, Historia de la Inquisición española (Madrid, Fundación Universitaria Española, 1983), II.

Martínez Díez, Gonzalo, Bulario de la inquisición española (Madrid, Editorial Complutense, 1998).

Millar, René, Inquisición y sociedad en el virreinato peruano (Santiago, Pontificia Universidad Católica de Chile, 1997).

Ruz BARrio, Miguel Ángel, El Conocimiento por parte de los indígenas de la Justicia Novohispana: el caso de Mateo Chimaltecuhtli (Cholula, siglo XVI), en Anuarios de Estudios Americanos, 66 (Sevilla., 2009) 2.

Solózano y Pereyra, Juan, Política indiana (Madrid, Biblioteca de Autores Españoles, 1972).

Tomás y Valiente, Francisco, Relación de la Inquisición con el aparato institucional del Estado, en Gobierno e instituciones en la España del Antiguo régimen (Madrid, Alianza Editorial, 1982).

Villagómez, Pedro de, Carta Pastoral de exhortación e instrucción acerca de la idolatría de los indios del arzobispado de Lima (Lima, 1647). 
